\title{
Studies on the Stability of Aluminium Chelates of Catecholdisulphonic Acid in Aqueous Solutions
}

\author{
REINO NASXNEN \\ Institute of Chemistry, University of Helsinki, Finland
}

\begin{abstract}
The complex formation between the aluminium ion and catecholdisulphonic acid $\left(\mathbf{H}_{4} \mathbf{A}\right)$ has been investigated. The stability constant of $\mathrm{AlA}^{-}$was determined. The effect of some added electrolytes on the stabilities of $\mathrm{AlA}^{-}$and AlAs- has been studied. The effects of potassium chloride and nitrate on the stability of $\mathrm{AlA}_{2}^{5-}$ were nearly equel. The effects of sodium perchlorate, chloride and nitrate were mutually nearly equal but differed considerably from the effect of potassium salts. The effect of one pentavelent ion (AlAs-) appeared to be nearly equal to that of five monovalent ions.
\end{abstract}

Tn a recent paper from this laboratory ${ }^{1}$, it was concluded that the types of Ithe complexes formed between the aluminium ion and catecholdisulphonic acid $\left(\mathrm{H}_{4} \mathrm{~A}\right)$ are $\mathrm{AlA}^{-}, \mathrm{AlA}_{2}^{5-}$ and $\mathrm{AlA}_{8}^{9-}$. At that time the equilibrium

$$
\mathrm{Al}^{3+}+\mathrm{H}_{2} \mathrm{~A}^{2-}=\mathrm{AlA}^{-}+2 \mathrm{H}^{+}
$$

was not investigated in detail. Data concerning equilibrium (1) are now presented.

The previous potentiometric method was used and the equilibrium constant

$$
K_{\mathrm{I}}=\left[\mathrm{AlA}^{-}\right]\left[\mathrm{H}^{+}\right]^{2} /\left[\mathrm{Al}^{3+}\right]\left[\mathrm{H}_{2} \mathrm{~A}^{2-}\right]
$$

was calculated from the equations

$$
\begin{gathered}
\left.\left[\mathrm{H}_{2} \mathrm{~A}^{2^{-}}\right]=\left(c-0.5 c_{\mathrm{B}}-0.5[\mathrm{H}+]\right) /\left(1+0.5 K_{3} /[\mathrm{H}+]\right)\right] \\
c^{\prime}=c-\left[\mathrm{H}_{2} \mathrm{~A}^{2-}\right]\left(1+K_{3} /[\mathrm{H}+]\right) \\
x=\left[\mathrm{H}_{2} \mathrm{~A}^{2-}\right] /[\mathrm{H}+]^{2} \\
K_{\mathrm{I}}=c^{\prime} / x\left(c_{\mathrm{A} 1}-c^{\prime}\right)
\end{gathered}
$$

where $c, c_{B}$ and $c_{A}$ are the total molar concentrations of tiron, sodium hydroxide and aluminium perchlorate, respectively. 
Table 1. Determination of constant $K_{\mathrm{I}}$ at $25^{\circ} \mathrm{C}$.

\begin{tabular}{|c|c|c|c|c|c|c|c|c|c|c|}
\hline \multicolumn{3}{|c|}{ Titration I: } & \multicolumn{4}{c|}{ Titration II: } & \multicolumn{3}{c|}{ Titration III: } \\
\cline { 1 - 6 } $\begin{array}{c}c \cdot 10^{3} \\
c_{\mathrm{A}} \cdot 10^{3}\end{array}$ & $\sqrt{I}$ & $\mathrm{p} K_{\mathrm{I}}$ & $c \cdot 10^{3}$ & $c_{\mathrm{A} 1} \cdot 10^{3}$ & $\sqrt{I}$ & $\mathrm{p} K_{\mathrm{I}}$ & $c \cdot 10^{3}$ & $c_{\mathrm{A} 1} \cdot 10^{3}$ & $\sqrt{I}$ & $\mathrm{p} K_{\mathrm{I}}$ \\
\hline 1.364 & 0.092 & 2.69 & 4.092 & 1.364 & 0.179 & 2.84 & 14.21 & 4.737 & 0.34 & 3.01 \\
1.357 & 0.089 & 2.68 & 4.071 & 1.357 & 0.178 & 2.84 & 13.93 & 4.639 & 0.34 & 3.06 \\
1.351 & 0.087 & 2.66 & 4.053 & 1.351 & 0.176 & 2.82 & 13.64 & 4.545 & 0.33 & 3.05 \\
1.341 & 0.084 & 2.64 & 4.023 & 1.341 & 0.174 & 2.82 & 13.37 & 4.455 & 0.32 & 3.06 \\
1.339 & 0.081 & 2.64 & 4.017 & 1.339 & 0.173 & 2.83 & 13.11 & 4.369 & 0.31 & 3.05 \\
1.333 & 0.077 & 2.63 & 3.999 & 1.333 & 0.172 & .2 .84 & & & & \\
\hline
\end{tabular}

In Table 1 the results of some titrations for the determination of the constant $K_{1}$ are presented. The ionic strength is calculated from $I=\frac{1}{2} \Sigma z_{1}^{2} c_{1}$. The constant $K_{\mathrm{I}}$ is seen to vary in a way to be expected from the UebyeHückel equation, which in this case has the form

$$
\mathrm{p} K_{\mathrm{I}}=\mathrm{p} K_{\mathrm{I}}^{\circ}+\frac{5.09 \sqrt{\bar{I}}}{1+\alpha \sqrt{I}}-B I .
$$

The results do not suggest the formation of the complex AlHA, a type which is found among the Fe(III) complexes of tiron ${ }^{2}$. The effect of addition of potassium chloride on the constant $K_{\mathrm{I}}$ was also investigated and the results are presented in Table 2 . These results can be represented satisfactorily by the equation

$$
\mathrm{p} K_{\mathrm{I}}=2.32+\frac{5.09 \sqrt{I}}{1+2.35 \sqrt{I}}+0.06 I
$$

On comparing the values in Tables 1 and 2, one sees they differ at higher ionic strengths, as would be expected from the differences in ionic medium.

The equilibrium constant of the reaction

defined by

$$
\mathrm{AlA}^{-}+\mathrm{H}_{2} \mathrm{~A}^{2-}=\mathrm{AlA}_{2}^{5-}+2 \mathrm{H}^{+}
$$

$$
K_{\mathrm{II}}=\left[\mathrm{AlA}_{2}^{5-}\right]\left[\mathrm{H}^{+}\right]^{2} /\left[\mathrm{AlA}^{-}\right]\left[\mathrm{H}_{2} \mathrm{~A}^{2-}\right]
$$

has been determined previously by Näsänen and Veivo ${ }^{1}$. They became

\begin{tabular}{|c|c|c|c|c|c|}
\hline$V \bar{I}$ & \multicolumn{2}{|c|}{$\mathrm{p} K_{\mathrm{I}}$} & $V \bar{I}$ & \multicolumn{2}{|c|}{$\mathrm{p} K_{\mathrm{I}}$} \\
\hline $\begin{array}{l}.084 \\
.32\end{array}$ & $\begin{array}{l}2.67 \\
3.26\end{array}$ & $\begin{array}{l}2.67 \\
\mathbf{3 . 2 5}\end{array}$ & $\begin{array}{l}1.02 \\
1.39\end{array}$ & $\begin{array}{l}3.90 \\
4.10\end{array}$ & $\begin{array}{l}3.91 \\
4.09\end{array}$ \\
\hline
\end{tabular}
aware that the points of both the second and the third buffer ranges of the titration curve give almost constant values for $K_{\mathrm{II}}$ and $K_{\mathrm{III}}$, respectively,

Table 2. Constant $K_{\mathrm{I}}$ in potassium chloride solutions at $25^{\circ} \mathrm{C}$.

Acta Chem. Scand. 11 (1957) No. 8 
Table 3. The effect of pentavalent ions $\mathrm{AlA}_{2}^{5-}$ on the equilibrium constant $K_{\mathrm{II}}$.

Titration I. $c / c_{\mathrm{Al}}=3$

\begin{tabular}{|c|c|c|c|c|c|}
\hline$c \cdot 10^{3}$ & $c_{\mathrm{B}} / c_{\mathrm{Al}}$ & $c^{\prime} / c_{\mathrm{A} 1}$ & $\mathrm{pH}$ & $V \overline{\frac{1}{2} \Sigma z_{1}^{2} c_{i}}$ & $V \sqrt{\frac{1}{2} \sum z_{1} c_{i}}$ \\
\hline 3.9 & 2.1 & 1.07 & 4.801 & 0.110 & 0.104 \\
\hline 3.9 & 2.2 & 1. & 5.017 & 0.1 & 0.105 \\
\hline 3.94 & 2.62 & 1.31 & 5.246 & 0.127 & 0.107 \\
\hline 3.93 & 2.91 & 1. & 5.438 & 0.134 & 0.108 \\
\hline 3.9 & 3.0 & $1 .($ & 5.607 & 0.145 & 0.110 \\
\hline 3.89 & 3.6 & 1.8 & 5.820 & 0.152 & 0.112 \\
\hline 3.888 & 3.79 & 1.89 & 5.972 & 0.155 & 0.113 \\
\hline
\end{tabular}

Titration II. $c / c_{\mathrm{Al}}=3$

\begin{tabular}{|c|c|c|c|c|c|c|}
\hline$c \cdot 10^{3}$ & $c_{\mathrm{B}} / c_{\mathrm{A} 1}$ & $c^{\prime} / c_{\mathrm{Al}}$ & $\mathrm{pH}$ & $V \overline{\frac{1}{2 z^{2}{ }_{\mathrm{i}}} c_{\mathrm{i}}}$ & $\sqrt{\frac{1}{2} \sum z_{i} c_{i}}$ & $\mathrm{p} K_{\mathrm{II}}$ \\
\hline 12.8 & 2.18 & 1.09 & 4.373 & 0.203 & 0.188 & 1 \\
\hline 12. & 2.7 & 1. & 4.732 & 0.225 & 0.190 & 7 \\
\hline 12.2 & 3.0 & 1.5 & 4.973 & 0.244 & 0.19 & \\
\hline 12.16 & 3.5 . & 1.75 & 5.235 & 0.262 & 0.196 & 7.5 \\
\hline 12.05 & 3.73 & 1.87 & 5.421 & 0.270 & 0.198 & 750 \\
\hline
\end{tabular}

Titration III. $c / c_{\mathrm{A} 1}=3$

\begin{tabular}{|c|c|c|c|c|c|}
\hline$c \cdot 10^{3}$ & $c_{\mathrm{B}} / c_{\mathrm{Al}}$ & $c^{\prime} / c_{\mathrm{Al}}$ & $\mathrm{pH}$ & $V \overline{\frac{1}{2} z_{i}{ }^{2} c_{i}}$ & $\sqrt{\frac{1}{2} \sum z_{1} c_{i}}$ \\
\hline $\begin{array}{l}58.8 \\
57.7 \\
56.6 \\
55.6\end{array}$ & $\begin{array}{l}2.35 \\
2.75 \\
3.17 \\
3.55\end{array}$ & $\begin{array}{l}1.18 \\
1.33 \\
1.58 \\
1.78\end{array}$ & $\begin{array}{l}3.802 \\
4.064 \\
4.240 \\
4.522\end{array}$ & $\begin{array}{l}0.435 \\
0.515 \\
0.550 \\
0.580\end{array}$ & $\begin{array}{l}0.404 \\
0.410 \\
0.416 \\
0.421\end{array}$ \\
\hline
\end{tabular}

although the increase in the concentrations of the ions $\mathrm{AlA}_{2}^{5-}$ and $\mathrm{AlA}_{3}^{9-}$ during the titrations causes a considerable change in ionic strength as calculated from $I=\frac{1}{2} \Sigma z_{i}^{2} \cdot c_{i}$. More complete measurements have since been carried out by the present author in the case of $\mathrm{AlA}_{2}^{5-}$. In Table 3 some titrations with the ratio $c / c_{\mathrm{A} 1}=3$ but with different total concentrations are recorded. The results are in agreement with Brönsted's theory of specific ionic interaction $^{3}$ in the sense that one pentavalent negative ion has nearly the same effect on $K_{\mathrm{II}}$ as five univalent negative ions. The quantity $\frac{1}{2} \sum z_{1} c_{i}$ also varies during the titration but much less than $\frac{1}{2} \Sigma z_{\mathbf{i}}^{2} \cdot c_{\mathbf{i}}$ and obviously the variation of $K_{\mathrm{II}}$ with $\frac{1}{2} \Sigma z_{\mathrm{i}} c_{\mathfrak{i}}$ is of the same order of magnitude as the accuracy reached in the case in question.

The specific ionic interaction in the case of equilibrium (9) was further investigated by means of some neutral salts. These results are presented in Table 4. From this table and from Fig. 1 one can see that sodium chloride, nitrate and perchlorate have a nearly equal effect. The effects of potassium chloride and nitrate are also mutually nearly equal but differ considerably from the effect of sodium salts. Thus these results are also in accordance with the theory of specific ionic interaction. 
Table 4. The dependence of $K_{\mathrm{II}}$ on ionic strength in solutions of some neutral salts.

\begin{tabular}{|c|c|c|c|c|c|c|}
\hline \multicolumn{4}{|c|}{$\mathrm{p} K_{\mathrm{II}}$} & \multicolumn{3}{|c|}{$\mathrm{p} K_{\mathrm{II}}$} \\
\hline$\sqrt{\frac{1}{2} \sum z_{1} c_{\mathrm{i}}}$ & $\left(\mathrm{NaClO}_{4}\right)$ & $(\mathrm{NaCl})$ & $\left(\mathrm{NaNO}_{3}\right)$ & $V^{\prime} \overline{\frac{1}{2} \Sigma z_{i} c_{\mathrm{i}}}$ & $(\mathrm{KCl})$ & $\left(\mathrm{KNO}_{3}\right)$ \\
\hline 0.108 & 8.13 & 8.13 & 8.14 & 0.108 & 8.13 & 8.13 \\
\hline 0.316 & 6.98 & 6.95 & 6.96 & 0.294 & 6.57 & - \\
\hline 0.612 & 6.28 & - & - & 0.313 & - & 6.43 \\
\hline 0.971 & - & - & 5.84 & 0.598 & 5.68 & - \\
\hline 0.998 & - & 5.79 & - & 0.962 & - & 5.34 \\
\hline 1.300 & - & - & 5.66 & 1.070 & 5.26 & \\
\hline 1.375 & - & 5.71 & - & $\begin{array}{l}1.305 \\
1.700\end{array}$ & $5 . \overline{14}$ & 5.24 \\
\hline
\end{tabular}

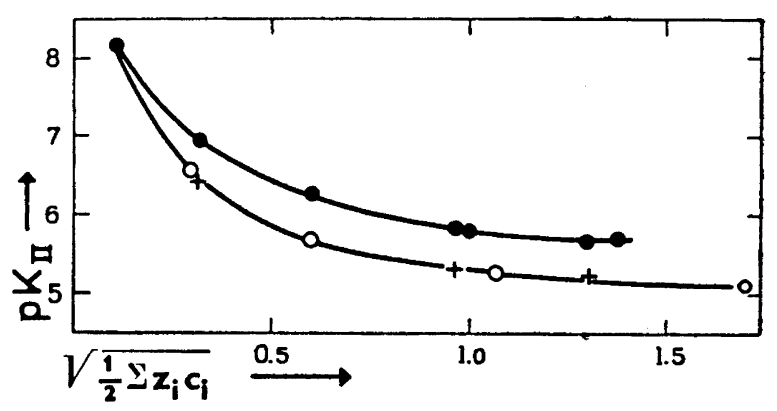

Fig. 1. The effect of some salts on the constant $K_{\mathrm{II}} \cdot \odot \mathrm{NaCl}, \mathrm{NaNO}_{3}, \mathrm{NaClO}_{4} \circ \mathrm{KCl}$, $+\mathrm{KNO}_{3}$.

Besides concentrations of negative ions, eqn. (10) also contains the concentration of hydrogen ion. The change in the activity coefficient of hydrogen ion with ionic medium is small compared with the respective changes of the activity coefficients of the high valent ions and obviously does not much influence the results.

For the calculation of the stability constants

$$
k_{v}=\left[\mathrm{AlA}_{\nu}^{(4 \nu-3)-}\right] /\left[\mathrm{Al}^{3+}\right]\left[\mathrm{A}^{4-}\right]^{\nu},
$$

the ionisation constants

$$
K_{3}=\left[\mathrm{H}^{+}\right]\left[\mathrm{HA}^{3-}\right] /\left[\mathrm{H}_{2} \mathrm{~A}^{2-}\right] \text { and } K_{4}=\left[\mathrm{H}^{+}\right]\left[\mathrm{A}^{4-}\right] /\left[\mathrm{HA}^{3-}\right]
$$

Table 5. Some values of the stability constants of aluminium chelates of catecholdisulphonic acid in potassium chloride solutions at $25^{\circ} \mathrm{C}$.

$\begin{array}{crrr}V \overline{\frac{1}{2} \sum z_{1} c_{i}} & & \log k_{1} & \log k_{2} \\ 0.1 & 16.6 & 30.0 \\ 1.0 & 14.9 & 28.4 \\ 2.0 & 14.6 & 28.1\end{array}$

Acta Chem. Scand. 11 (1957) No. 8 
are needed. One obtains

$$
k_{1}=K_{\mathrm{I}} / K_{3} K_{4} ; \quad k_{2}=K_{\mathrm{I}} K_{\mathrm{II}} / K_{3}^{2} K_{4}^{2} \text { and } k_{3}=K_{\mathrm{I}} K_{\mathrm{II}} K_{\mathrm{III}} / K_{3}^{3} K_{4}^{3}
$$

The third and fourth ionisation constants have been determined recently by the present author 4. The values of $k_{1}$ and $k_{2}$ at various ionic strength in potassium chloride solutions are given in Table 5.

\section{REFERENCES}

1. Näsänen, R. and Veivo, J. Suomen Kemistilehti B 29 (1956) 213.

2. Schwarzenbach, G. and Willi, A. Helv. Chim. Acta 34 (1951) 528.

3. Brőnsted, J. N. J. Am. Chem. Soc. 44 (1922) 877, 938; 45 (1923) 2898. Cf. Olson, A. R. and Simonson, T. R. J. Chem. Phys. 17 (1949) 348, 1167, 1322; Kilpi, S., Mikkola, K. S. and Valanki, M. K. Ann. Acad. Sci. Fennicae II. Chem. 52 (1953).

4. Näsänen, R. Suomen Kemistilehti B 30 (1957) 61.

Received May 9, 1957. 